\title{
CONFESIÓN, PALABRA Y PODER: EL MISERABLE NOMBRE FEMENINO ${ }^{1}$
}

Confession, word, and power: the miserable womanly existence

\author{
Jimena Castro Godoy*
}

\section{Resumen}

Entre la abadesa medieval alemana Hildegard von Bingen (siglo XII) y la monja clarisa chilena de fines del siglo XVII sor Úrsula Suárez existe una gran distancia histórica y cultural. Sin embargo, algo las aproxima enérgicamente, tal y como si hubieran sido hermanas del mismo claustro. Y esta aproximación no consiste en la vestimenta de hábitos o la proclamación de votos de pobreza, obediencia y castidad, si no que es, por sobre todo, la peripecia que ambas tuvieron que realizar para poder relatar sus experiencias espirituales: pedir el permiso de una figura masculina en el caso de Hildegard, y someterse a la obediencia de esta misma figura en el caso de Úrsula. En este trabajo me propongo exponer cómo los discursos de las monjas que han escrito se subordinan a la aprobación de un modelo de poder y autoridad.

Palabras clave: Hildegard von Bingen, Úrsula Suárez, discurso, convento, poder.

Abstract

Among the medieval German abbess Hildegard von Bingen (XII Century) and the Chilean late seventeenth century Clarisse Sister Ursula Suárez there exists a great historical and cultural distance. However, something strongly approximates them as if they were sisters of the same cloister. And this approach is not the clothing habits or the proclamation of vows of poverty, obedience and chastity, but it is, above all, the adventures that both had to live through in order to describe their spiritual experiences: ask permission of a male figure in the case of Hildegard, and submit to the obedience of this same figure in the case of Ursula. In this paper we propose to show how the discourses of the nuns who have written are subordinated to the approval of a model of power and authority.

Key words: Hildegard von Bingen, Úrsula Suárez, Speech, Convent, Power.

\footnotetext{
${ }^{1}$ Este artículo pertenece a una versión ampliada y revisada de una ponencia leída en el encuentro "De monjas a guerrilleras: mujer, arte y pensamiento", del Instituto de Estudios Avanzados de la Universidad de Santiago de Chile.
} 


\section{Jimena Castro Godoy}

\section{INTRODUCCIÓN}

Un monasterio o convento es un edificio pensado para ser habitado por monjes o monjas. Desde ahí, estas personas consagradas en pobreza, obediencia y castidad a Dios y a su orden religiosa, rezan y trabajan por la salvación de ellos y la del mundo. Monasterio y monje/a provienen del griego "mono", que significa [uno solo]. El fin del monje/a es hacerse uno solo con Dios en lo que muchos llaman desposorio espiritual. En efecto, la imagen de la monja como la esposa de Cristo es recurrente en toda la tradición monástica. La virgen, viuda o exprostituta que ingresa al convento para dedicar su alma y su cuerpo al divino esposo, conforma una verdadera y nueva familia: las monjas son todas hermanas que obedecen a una madre superiora, quien a su vez se guía por el confesor del monasterio, el padre espiritual de todas estas mujeres.

En el confesor debe volcar la monja toda su intimidad. Sueños, deseos y pensamientos son transmitidos a este hombre que en la Edad Media ejercía la cura monialium. La palabra cura significa "cuidado". La cura monialium era el ejercicio del cuidado espiritual de las monjas. De ahí que hoy hablemos de cura para referirnos al sacerdote. Por eso la cura monialium es en la Edad Media un ejercicio, un trabajo, una santa y necesaria actividad, pues eran muchos los peligros que amenazaban a estas mujeres, tan dadas al melodrama y la exageración. $^{2}$

Evidentemente el trabajo de este hombre era (y lo sigue siendo) aplicable solo a los monasterios femeninos. Los monjes, en general, se dejan guiar por su abad o por el maestro de novicios; no es necesaria, para los monasterios masculinos, la presencia de alguien externo para realizar la guía. Ya tienen con ellos la figura del padre, pero no la de la madre.

La monja que se somete a su confesor debe obedecerle en todo. Emblemático es el caso de Francisco de Sales (1567-1622), quien ordena a su dirigida espiritual, Juana de Chantal (1572-1641), a dejarlo todo con el fin de ayudarlo en la fundación de la Orden de la Visitación de Santa María. Juana era una mujer viuda y con hijos, quien, obediente al deseo de Dios y al de Francisco, inicia la fundación de esta orden religiosa. Tanta fue la desaprobación de sus hijos a la decisión de su madre, que una de ellas incluso la imita y también ingresa a la orden, aunque más adelante abandonara los hábitos y formara una familia.

Así, el camino de la monja no es un camino autónomo. Depende siempre de este hombre elegido por su criterio y delicadeza para orientar las conciencias de estas mujeres que no pueden regular por sí mismas su camino espiritual. De hecho, las monjas, a pesar de cumplir con los mismos votos que los monjes, requerían con mucha mayor energía estar encerradas. Mientras los monjes

\footnotetext{
${ }^{2}$ Ver Hamburguer, Jeffrey. "Art. Enclosure and the Pastoral Care of Nuns", en The Visual and the Visionary. Art and Female Spirituality in Late Medieval Germany. Zone Books: New York, 1998. 
podían moverse por ciudades y pueblos, las monjas necesariamente deben respetar la clausura. Michel Foucault, en Vigilar y castigar relaciona el encierro con el ejercicio de la disciplina: "La disciplina procede ante todo a la distribución de los individuos en el espacio (...) La disciplina exige a veces la clausura, la especificación de un lugar heterogéneo a todos los demás y cerrado sobre sí mismo" (164). Se encierra, entonces, el cuerpo de la monja y con él, también su conciencia.

Y es aún más difícil el camino de la monja que entra al monasterio sin vocación. Existen muchos casos y testimonios de mujeres que sí veían la vida monástica como el único camino deseado para ellas. De hecho, impacta el testimonio de vírgenes como Cristina de Markyate (muerta en 1160) quien, a pesar del deseo de su familia, se negaba a contraer matrimonio, ya que desde muy pequeña había hecho votos de castidad. Obligada a casarse, le ruega a su marido que no se acerque a su cama y, después de un tiempo, arranca de su casa marital para vivir como ermitaña. Similar es el caso de Ángela de Foligno (1248-1309), quien reconoce haber rezado por la muerte de su marido y sus hijos para poder entregarse completamente a su Dios.

Pero también los monasterios acogieron a varias mujeres que vivían ahí en contra de su voluntad. Una de ellas es Arcangela Tarabotti (1604-1652), quien aprovechó su talento literario para denunciar a los padres que forzaban a sus hijas a abrazar la vida monástica. En general, las familias enviaban a las hijas que tenían menos posibilidad de casarse a los conventos considerando su apariencia física. Otro motivo que inspiraba a los padres a decidir este camino por sus hijas era el gran coste económico que significaba casarlas, ya que la dote que se ofrecía a los conventos era bastante menor que la ofrecida a los futuros maridos.

Es normal también que en los conventos se replicara la estructura social de la vida mundana. La Congregación de Obispos declaró y aprobó en el año 1627 la jerarquización en los monasterios que establece la división entre monjas sirvientas (llamadas "indias" o "chinas" en nuestro continente) y monjas dedicadas exclusivamente al ejercicio espiritual, que eran llamadas "monjas del coro". Estas últimas no podían realizar esfuerzos mayores, ya que podrían adquirir algún tipo de enfermedad. Las monjas sirvientas, en cambio, debían demostrar, antes de ingresar a la orden, que poseían la fuerza necesaria para llevar objetos pesados y soportar exigentes jornadas de trabajo. Debían tener entre veinte y cuarenta años y demostrar buena salud. La dote que entregaban era bastante menor al resto de las monjas y la exclusión a la que se sometían dentro del convento era de tal nivel, que solo podían ir a rezar el oficio divino cuando ya hubieran terminado sus obligaciones. Tampoco participaban de las decisiones políticas del convento, aunque a veces podían asistir a las votaciones, pero solo a observar. Esta situación terminó legalmente en los años sesenta 


\section{Jimena Castro Godoy}

gracias al Concilio Vaticano II que prohibió todo tipo de distinción social dentro de los conventos.

Podremos comprender entonces por qué Octavio Paz afirma que, en los tiempos de Sor Juana Inés de la Cruz el convento era el lugar perfecto para elaborar y transmitir chismes junto a todo tipo de intrigas. Así, el confesor, que debía velar por la salud espiritual de sus hijas, tenía que revisar también su relación con las demás hermanas. El confesor era...

un hombre preparado e instruido en las particulares cuestiones de esas mujeres monjas (...): sus temores o tendencias al escrúpulo, sus rencillas y rivalidades internas, sus fervientes deseos de ser las más perfectas (...) debían hacer presente "las angustias de su alma" a un confesor para que este opinara sobre la calidad de las faltas o la dirección de su espíritu (Araya, 2003:161).

Así, las monjas — sin o con vocación - están siempre expuestas a lo que Rodrigo Cánovas llamó "la generación simbólica de la autoridad bajo la oposición masculino /femenino" (101).

$\mathrm{Y}$ es el ejercicio de esta autoridad el que me interesa compartir, específicamente en los casos de Hildegard von Bingen (Alemania, 1098-1179) y Úrsula Suárez (Chile, 1666-1749). Ambas monjas experimentaron particulares relaciones con la escritura: Hildegard requiere del permiso masculino para revelar sus visiones y a Úrsula se le impone escribir su autobiografía supuestamente en contra de su voluntad. ${ }^{3}$

Si volvemos a la imagen del confesor, podemos recordar que, tras el Concilio de Trento (1550), cada monja adquirió el "derecho" de contar con un confesor particular para que la oriente en su vida espiritual. Esta relación se daba mediante la dirección espiritual y por la confesión, ambos medios de orientación elaborados de manera oral, es decir, por la conversación. Sin embargo, en algunos casos muy especiales el confesor podía solicitarle a la monja que escribiera algunas experiencias ya que la escritura "fue un recurso recomendado para aquellas que tenían necesidad de guía especializada en un camino de perfección, o bien, que padecían angustias que solo el papel podía soportar" (Araya, 2003:161-2). Escribían aquellas mujeres que eran favorecidas con especiales carismas, como éxtasis o visiones. Plasmar en el papel estas

\footnotetext{
${ }^{3}$ Para esta relación es fundamental considerar los contextos en los que vivieron ambas monjas. Hildegard se encontraba en un universo en el que la participación femenina en la espiritualidad no era todavía condenable, ya que ni ella ni sus hermanas osaron inmiscuirse en asuntos teológicos -propios de los hombres-, como sí ocurriera muchas veces años después con las beguinas (el caso de Margarita Porete es emblemático). El mundo de Úrsula se encontraba amenazado por una serie de prácticas ligadas al iluminismo que incrementaron la vigilancia sacerdotal, y muchos confesores tenían como misión la persecución de esta herejía tan popular en el mundo novohispano.
} 
experiencias ayudaría al confesor a analizar la procedencia de estos dones, pues bien podrían ser inspiración divina como también demoníaca. Eran, generalmente, documentos que no tenían por objeto ser publicados. Y es gracias a ellos que logramos tener acceso a la vida y pensamientos de estas mujeres.

Úrsula declara haber sido obligada a escribir e Hildegard pidió autorización para hacerlo, permiso que le fue otorgado. Para Úrsula la escritura de su autobiografía era una verdadera penitencia que, como pudiera, intentaba esquivar, incluso con la enfermedad. Se enfermaba también Hildegard von Bingen, pero justamente por la ausencia de posibilidad de escribir. Sin embargo, palabra y silencio, discurso y afonía, fueron siempre modulados por la misma figura, la masculina.

Pretendo demostrar en esta investigación cómo la figura de autoridad, por medio de ciertos giros lingüísticos utilizados por estas dos mujeres, se invierte para terminar el poder del discurso en manos de estas débiles monjas. Para lograrlo, reviso el concepto de disciplina propuesto por Michel Foucault en Vigilar y castigar donde el autor indaga en cómo se han elaborado estos sistemas - los disciplinarios - en los que se incluyen, ciertamente, los conventos. Por eso es que Foucault nos ayudará a entender cómo funciona este tipo de instituciones y así comprendamos lo que ahora intento proponer: que las mujeres que escriben revierten la autoridad masculina.

\section{ESCRITURA EN LOS CONVENTOS}

Las reglas monásticas albergan dentro de ellas, dependiendo de la orden religiosa, diferentes estipulaciones para el comportamiento de las monjas. Algunas constituciones se preocuparán de enfatizar la pobreza y otras la caridad, pero la común a todas es, sin lugar a dudas, la obligación de mantener silencio. El día de una monja se configura de acuerdo con ciertas actividades que deben realizar, orientadas principalmente por el Oficio Divino y el trabajo manual. Habrá solo algunos momentos de recreo en el que las monjas pueden conversar, pero esta conversación debe versar solo sobre asuntos productivos para el espíritu; hablar de ellas mismas es considerado un pecado de soberbia del que deberán pedir perdón de manera pública.

Sin embargo, este silencio muchas veces queda anulado y lo hace principalmente en dos instancias: en la confesión, que es cuando la monja pide perdón por los pecados y omisiones que ha cometido, es decir, habla de sí misma con el fin de expiar malos pensamientos, actitudes y obras; y la segunda instancia es ciertamente la escritura, aunque no todas estén llamadas a hacerlo. Las que sí están llamadas a escribir no lo pueden hacer sobre cualquier tema. Es muy común que la monja letrada del monasterio escribiera la historia del convento, algunas vidas de santos o comentarios a la regla del fundador de la orden, es decir, textos que podríamos considerar más bien neutros o que al 


\section{Jimena Castro Godoy}

menos no están escritos desde el yo. También se conservan cartas que se enviaban a príncipes, obispos u otras figuras importantes. De hecho, en el epistolario de Hildegard von Bingen figuran personajes como Bernardo de Clairvaux, el papa Eugenio III, Enrique II de Inglaterra y Federico I. Y con esto anticipo el gran poder que logró alcanzar Hildegard desde su voz femenina.

De todos los escritos de monjas, el que me interesa analizar es aquel en el que estas mujeres logran hablar de ellas mismas. A pesar del silencio impuesto en las reglas, es misteriosa la enorme cantidad de relatos autobiográficos encontrados en los monasterios medievales y coloniales. De hecho, Isabelle Poutrin llega a afirmar que los conventos fueron verdaderos talleres de escritura autobiográfica y Silvia Evangelisti nos cuenta que fueron 113 las historias espirituales que se encontraron entre fines del siglo XVI y la primera mitad del siglo XVII en los monasterios de España.

Veremos entonces, considerando este panorama, de qué manera se relacionaron con la escritura las dos monjas que ahora quiero presentar, y cómo, mediante ese ejercicio, desafiaron la disciplina impuesta, logrando subvertir la autoridad.

\section{LA EXPERIENCIA DE HILDEGARD VON BINGEN}

"A los tres años de edad vi una luz tal que mi alma tembló, pero debido a mi niñez nada pude proferir acerca de esto" (Cirlot, 2009:51). Así es como Hildegard von Bingen (1098-1179) narra sus primeras experiencias visionarias. Solo a los 43 años esta abadesa pudo revelar aquellos extraños procesos espirituales que vivía desde pequeña:

Y he aquí que fue en el año cuarenta y tres del curso de mi vida temporal, cuando en medio de un gran temor y temblor, viendo una celeste visión, vi una gran claridad en la que se oyó la voz del cielo y dijo: "Frágil ser humano (...) di y escribe lo que veas y oigas" (Cirlot, 2008:47).

A pesar de que sea el mismísimo Dios el que le ordena a la visionaria revelar lo que ha visto, aun así Hildegard teme escribir sus revelaciones por su condición femenina. Así es como redacta una angustiada carta a Bernardo, obispo de Clairvaux, en la que expone su temor:

Padre, estoy muy angustiada por una visión que se me apareció en el espíritu como misterio, pues nunca la vi con los ojos exteriores de la carne. Yo, miserable de mí y aún más miserable en nombre femenino, vi desde mi infancia grandes maravillas que mi lengua no podría relatar si el Espíritu de Dios no me hubiera enseñado a creer (Cirlot, 2009:188).

Bernardo le responde a Hildegard con una tibia aprobación, confiando el abad en las cualidades visionarias de la monja. Por el mismo período, en el año 1148, Hildegard se dirige también al papa Eugenio III con el fin de que la 
autorice a revelar su obra ${ }^{4}$, quien le responde en 1151: "Consideramos que tu alma arde en el fuego del amor divino de tal modo que no tienes necesidad de exhortación alguna para obrar bien" (Cirlot, 112). Sin embargo, ya en 1148 y durante el sínodo de Trier el papa solicitará al abad de Disibodenberg y al arzobispo de Mainz que preparen una comisión para observar la obra de la vidente. El apoyo de Bernardo de Clairvaux fue fundamental para que Eugenio III aprobara la obra de Hildegard, llegando incluso el papa a leer frente a los padres sinodales un fragmento de Scivias, su primera obra profética escrita entre 1141 y 1151 .

Así es como esta monja, desde su temor y temblor, desde el miedo a escribir a partir de su nombre femenino, terminó por convertirse en una importante figura de su tiempo. Su imagen de profetisa, santa y visionaria se expandió gracias a los largos viajes que Hildegard realizó. Sin embargo, esta autoridad no llegó a su vida de manera gratuita. Revisemos un poco cómo fue su proceso visionario y cómo este terminó siendo redactado.

Hildegard von Bingen era una mujer que no sabía escribir doctamente y que necesitó siempre de un secretario que anotara lo que ella dictaba. El primero fue el monje Volmar y cuando este murió, Hildegard se valió de otro monje, Gottfried, quien también comenzó a redactar su vida. Esta Vita nos proporciona datos importantes en torno a la capacidad visionaria, profética y milagrosa de la santa. Además, tiene la particularidad de ser escrita, aunque fragmentariamente, en primera persona: Gottfried y Theoderich (monje que terminó de escribir la Vita una vez muerta Hildegard) se preocuparon de no intervenir demasiado en las palabras que dictaba la visionaria, que finalmente serían las palabras del mismo Dios. En esta biografía se demuestra cómo las visiones que recibía Hildegard eran un verdadero peso para ella: "Agotada de todo esto, pregunté a mi nodriza si veía algo aparte de las cosas exteriores, y me respondió que nada, porque no veía nada de aquello" (Cirlot, 51). La angustia de Hildegard consiste no solo en la extrañeza de estas visiones y audiciones, ${ }^{5}$ sino que también se produce por la inseguridad que le significa la posibilidad de escribirlas. Todo lo revelado a la visionaria debe necesariamente ser transmitido: "Y lo que había

\footnotetext{
4 “Autoriza este escrito para que pueda ser oído por los que me aceptan y haz que sea verde en jugo de dulce gusto y que sea raíz de ramas y hojas que vuelen contra el diablo, y vivirá eternamente" (Cirlot, 2009:111).

${ }^{5}$ Las palabras que Hildegard profiere al que sería su segundo secretario nos dicen que la experiencia visionaria es simultánea a la experiencia auditiva. En efecto, los textos proféticos - Scivias, Liber vitae meritorum y Liber divinorum operum - primero describen una visión y luego transmiten lo que se oyó en ella. La visión de Hildegard es entonces también audición, cumpliendo esta última la función de explicar lo visto. En el Scivias por ejemplo, nos enfrentamos al siguiente relato: "Entonces vi un aire muy luminoso en el que escuché, oh maravilla, todas las músicas con todos los misterios que el Señor me había revelado" (487). Visión y audición se tornan casi indiferenciables en aquella música reveladora de misterios.
} 


\section{Jimena Castro Godoy}

visto en el interior, lo exponía lo mejor que podía con palabras y escritos" (Cirlot, 43). Célebre es la relación del silencio de Hildegard con su enfermedad. Cuanto más callaba, más enfermaba y la experiencia visionaria no quedaría completa hasta ser transmitida por escrito. Así al menos se lo cuenta a Bernardo cuando le pide permiso para escribir:

Dulce y buen padre, me he puesto en tu alma, para que me reveles por tu palabra si quieres que diga esto públicamente o que guarde silencio, pues gran trabajo tengo con esta visión y no sé hasta qué punto puedo decir lo que vi y oí. De vez en cuando estoy postrada en el lecho muy enferma a causa de esta visión, porque callo, de modo que no me puedo levantar (Cirlot, 188).

En este sentido, la enfermedad de Hildegard cumple dos funciones. La primera es dar cuenta de lo que Foucault llama "el momento histórico de las disciplinas" (160) que es

el momento en el que nace un arte del cuerpo humano que no tiende únicamente al aumento de sus habilidades, ni tampoco a hacer más pesada su sujeción, sino a la formación de un vínculo que, en el mismo mecanismo, lo hace tanto más obediente cuanto más útil, y viceversa (Foucault, 2009:160).

Y, en segundo lugar, veo en la enfermedad de esta monja una subversión del binomio masculino/femenino ligado a la autoridad, explicado por Cánovas. Esto porque Hildegard se encarga justamente de utilizar su enfermedad como una treta que permita la escritura. Para Hildegard la palabra escrita es la solución a la enfermedad corporal, pues al momento de nombrar lo sucedido logra recuperar la salud y así la visión, al ser revelada, es también arrojada del propio cuerpo. De este modo, el cuerpo se constituye en el objeto que dice el poder, tal y como afirma Foucault: "El cuerpo humano entra en un mecanismo de poder que lo explora, lo desarticula y lo recompone" (160). El cuerpo se hace el papel donde se escribirán estas visiones.

Analizaremos con mayor profundidad estos vínculos una vez que conozcamos la relación que Sor Úrsula Suárez también mantuvo con la tríada poder-cuerpo-escritura.

\section{EL CASO DE ÚRSULA SUÁREZ}

Úrsula Suárez (1666-1749) o Úchula, como la trataban de pequeña, se define a sí misma como la "santa comedianta" de Dios y "una santa muy alegre". Ingresó al convento de las Clarisas de Santiago de Chile a los 12 años de edad (Hildegard ingresó a los 14) y fue obligada por su confesor a escribir su autobiografía. Este relato es escrito durante 25 años y el confesor diariamente la 
proveía de papel para ser llenado con las peripecias de la monja. Estos escritos eran después retirados por el mismo confesor con el fin de ser revisados. El texto, llamado por su autora Relación de las singulares misericordias que ha usado el Señor con una religiosa, indigna esposa suya, previniéndole siempre para que solo amase a tan Divino Esposo y apartase su amor a las creaturas; mandada escrebir por su confesor y padre espiritual, es publicado en Chile en el año 1984, a pesar de que Úrsula amenazara a sus confesores con desearles la muerte si es que llegaban a publicarlo o comentarlo. Y claro, en la autobiografía están contenidos principalmente los pecados y tentaciones de esta clarisa.

La obra está dividida en catorce cuadernos y, desde el primero de ellos, Úrsula evidencia la enorme vergüenza que siente al escribir sobre estos asuntos

para que yo cumpla con la obediencia de vuestra paternidad, y vensa tanta dificultad y resistencia como tiene mi miseria en referir las cosas que tantos años han estado en mi sin quererlas desir, por ser mi confución tanta y con tan suma verguensa que me acobarda; mas, atenta que sera ésta la divina voluntad ordenada por la de vuestra paternidad, con lagrimas referir toda mi vida pasada, que anegada en el mar de mis Iagrimas no sé como principiar (Sor Úrsula Suárez, Relación autobiográfica, 90).

Reclama la monja sobre lo excesiva que es su penitencia, pues escribir sobre ella misma es un peso que evidentemente no puede cargar: "No se como escrebirle, padre mio; levanteme esta penitencia y deme otra cualquiera" (154). Otro de sus argumentos es que no quiere escribir porque no sabe hacerlo:

desir las cosas que han pasado por mi, ni hallo término adecuado para poder esplicarlo, ni a mas podra llegar el trabajo que tengo, que careser de entendimiento. ¿No conose muy bien vuestra paternidad esto, pues, lo tiene visto en lo que le tengo escrito?; ¿Para qué es molestarme, padre mio, en lo que no sé haser? (155).

¿Por qué imponerle a la monja esta penitencia tan difícil de llevar?, ¿Cuál es el pecado que cometió? Lamentablemente para nosotros, y afortunadamente para Úrsula, no existe registro de aquella falta y, probablemente, esta fue revelada en la confesión, es decir, de forma hablada o en un cuaderno previo al que no tenemos acceso. Sin embargo, en el transcurso de la Relación autobiográfica se pueden observar algunos momentos en que la monja confiesa tener visiones y participar también en conversaciones con Dios. Se trata de lo que ella llama las "hablas". Siendo partícipe del plan divino, la monja se muestra como una mujer privilegiada por recibir tan naturalmente esta comunicación divina. Para Rodrigo Cánovas el castigo de Úrsula puede haber sido por "transgredir los espacios culturales delimitados para la mujer chilena 


\section{Jimena Castro Godoy}

(La Colonia). Ella sería, entonces, portadora de una identidad femenina nueva o censurada" (99). Pero ¿Cómo es esta nueva identidad?

Una aparente ligereza con la que enfrenta los temas "serios" o "provechosos", su afán por contar y leer historias solo porque son entretenidas y no porque son para el progreso espiritual configuran en Úrsula un nuevo perfil femenino y monástico:

ni siquiera un libro entero he lido, sino de 1os que hallo, un pedasito; y esto es verdad, porque soy tan perversa que ni la cartilla paso entera: no me acuerdo, padre, que jamas un libro ha llegado a pasar, que en todo he sido la suma de la maldad; porque, si tomaba un libro, era por entretinimiento y no para aprovecharme de ello (Sor Úrsula Suárez, 149).

Adicionalmente, la monja se ocupa de recordarle al confesor que está escribiendo esa autobiografía solo por obediencia: "A mucho me obliga la obediencia de vuestra paternidad" (149), "p[r]osigo en la obediencia de vuestra paternidad, aunque con repugnancia mia" (120), "me lo mando su paternidad, imponiendo su obediencia" (190), "doy principio a su obediencia" (217), "por cumplir con su obediencia" (256), entre tantas ocasiones más. Si para Foucault las organizaciones de disciplina tienen como fin "formar individuos bien sometidos" (79), los individuos debieran aceptar que la obediencia es parte de un sistema que "tienen por objeto principal un aumento del dominio de cada cual sobre su propio cuerpo" (Foucault, 160). Y es justamente el dominio del cuerpo el que se le escapa a Úrsula, pues pareciera tener demasiada conciencia de su presencia al gustar tanto de la entretención y el humor. En efecto, Úrsula no solo lee historias entretenidas, sino que también las cuenta:

soy tan habladora que me buscaban las religiosas que las divirtiera, y me llamaban la historiadora; yo les contaba historias y ejemplos, porque tenia memoria felis, que 1 os sermones que oia 1 os referia, y cuanto leia se imprimia en mi memoria, la cual me falta ahora. Entre lo que les contaba salia con chansas, disiéndoles: "Han de saber que he de ser santa, y no asi como quiera, que no ha de haber en la Iglesia de Dios santa tan disparatada" (245).

Pareciera que este sutil uso del placer que significa entretenerse con historias de poco valor espiritual alarma al confesor y pone en riesgo su autoridad. Cabe notar que los ejercicios de disciplina, de acuerdo con Foucault, consisten en "pequeños ardides dotados de un gran poder de difusión, acondicionamientos sutiles, de apariencia inocente, pero en extremo sospechosos" (161). Por eso es que Úrsula pareciera percibir que en el pequeño gesto de revelar su interioridad a un confesor existe un dominio a su conciencia que no quiere aceptar. Por eso es que también amenaza con la enfermedad y con ella justifica también los atrasos de la escritura de la autobiografía. 
Así entonces, Úrsula no solo se dedica a relatar sus pecados, sino que está constantemente intentando justificarse a ella misma ante sus confesores, queriendo siempre validar esta imagen de niña que juega dentro de un espacio serio y adulto. Esta imagen infantil es justamente la que la misma religiosa siente que hace falta en el ejército de santos de la Iglesia.

\section{ESCRIBIR EN LA DISCIPLINA}

"La visibilidad es una trampa" (121), afirma Michel Foucault al describir el panóptico de Bentham. El individuo ahí encerrado "es visto, pero él no ve; objeto de una información, jamás sujeto en una comunicación" (121). El momento en que la monja es impulsada a revelar su interioridad acepta ingresar a este panóptico en el que es observada, pero sin poder observar. Entran a este panóptico Hildegard y Úrsula, pero, de alguna forma, logran ellas mirar al exterior. La vigilancia, si bien es permanente, es también esquivada por estas monjas, ¿De qué manera? En primer lugar, tanto Úrsula como Hildegard se encargan de destacar su lugar de enunciación: el miserable nombre femenino.

La abadesa alemana se preocupa en múltiples ocasiones de mostrarse como un ser indigno y pequeño porque es mujer. En la célebre carta a san Bernardo suspira: "con dolor me lamento ante ti, pues soy talada del árbol caído del lagar en mi naturaleza, nacida de la raíz que por sugestión del diablo salió de Adán, por lo que él mismo fue expulsado al mundo peregrino" (108). En otra oportunidad, al dirigirse al papa Eugenio III se presenta como "pobrecita forma" (111); a Odo de Soissons le confiesa: "tiemblo mucho debido a la humilde forma que hay en mí" (114) y a una congregación de monjas les señala: "La fuente viva dice: la mujer se mantiene oculta en la habitación con gran vergüenza, pues la serpiente le insufló grandes peligros de una horrible lascivia" (118). Sin embargo, esta imagen de mujer pobre por su propia condición queda salvaguardada por su carácter visionario. Una vez que Hildegard se deja ver como un recipiente insignificante de las revelaciones de Dios, da a entender a la vez que, a pesar de su condición, es capaz de percibir las visiones adoptando otra voz. A su amiga Elisabeth von Shönau le escribe: "Yo, pobrecita forma y recipiente de barro, digo esto, no de mí, sino desde la serena luz" (125), al obispo de Bamberg, Eberhard, le explica: "Oh padre, yo, pobrecita forma, he mirado a la verdadera luz y, según lo que vi y oí en la visión verdadera y me fue expuesto lo que tú me pediste que expusiera" (130). Al monje Guibert de Gemblaux, al preguntarle sobre la cualidad de las visiones de Hildegard, le responde: "Estas palabras que digo no son de mí ni de ningún otro hombre, sino que las profiero según la visión que recibí de lo alto" (140).

Así, la protección de la que se vale esta mujer consiste en trasladar su voz enunciadora femenina a la de la revelación de la luz divina, es decir, a la del mismo Dios. Entonces el discurso se hace válido ya no desde su condición de mujer, sino que desde su condición de visionaria. A pesar de que Hildegard crea 


\section{Jimena Castro Godoy}

realmente en que es receptáculo de las revelaciones divinas, igualmente utiliza un discurso en el que su propia personalidad está dividida: una porción de ella es esta minúscula mujer incapaz y, otra, la voz de la luz viviente, aquella voz que, por provenir directamente de Dios, no puede ser refutada.

Por su parte, Úrsula Suárez se queja de que los sacerdotes quieran involucrar a mujeres en temas que, tradicionalmente, han sido de hombres. Se refiere particularmente a la teología. Desligándose de la racionalidad (pues no sería asunto de mujeres), Úrsula pareciera defender sus incursiones místicas y visionarias:

¿Dejó Dios para osiosos estos Evangelios?: aunque las mujeres no 1os entendemos, ¿Mienten las Escrituras y 1os testos?; ¿Para que ponen a las mujeres en aprietos en lo que no sabemos ni hemos estudiado en ellos, en ves que nos habian de enseñar en ello?; ¿Es bueno, por mi vida, que nos metan en teologia cuando la puente de los gansos no hemos pasado? (135).

Adicionalmente, repele el carácter femenino: "con el enojo desia estos disparates que de las mujeres ya se sabe no tienen mas defensa que la lengua" (144), e incluso amenaza a su padre espiritual, indicándole que si divulgara esta autobiografía se estaría comportando como las mujeres:

Hise yo esto por no haser publicos mis estremos; mas no valió esto, porque las que salieron lo divulgaron en el convento, no dándome pequeña mortificacion en haberlo dicho, habiéndoselo pedido; mas las mujeres no podemos dejar nuestra propiedad, que nada podemos callar, y en mi ha sido mas que prodigio, que esto en tantos arios no lo haya dicho; solo de vuestra paternidad lo fio, y le encargo que mas que yo ha de guardarlo, que si se lo cuento es para que jamas propale a ninguna persona mi secreto: mire vuestra paternidad lo que hase (196).

Define sor Úrsula aquí la función del hombre y la de la mujer, quien debe confesar y contar todo, y el hombre debe guardar esos secretos. A pesar de las habladurías a las que tanto se someten las mujeres, es la misma palabra la que finalmente las va a liberar: "le propuse mi argumento: que las mujeres solo con palabras nos defendemos" (196). Y esta parece ser la estrategia de Úrsula, utilizar las mismas palabras que la castigan para establecer su defensa.

No quiero dejar pasar un episodio relatado en la Relación autobiográfica en el que Úrsula cuenta que cuando era pequeña formó parte de una conversación que fundaría el objeto de su batalla, que es vengar a las mujeres de las maldades de los hombres: "que todos mis pecados fueron engañar a los hombres por vengar a las mujeres por las que ellos han burlado, y desde antes de mudar los dientes empesé a vengar a las mujeres con grande empeño" (231). Esto porque Úrsula habría escuchado de boca de unas tías cómo el marido de una de sus amigas la había engañado. Además, la monja narra cómo cuando era 
pequeña podía observar por una rendija los actos sexuales en los prostíbulos, que ella llamaba "casamientos" por ser muy común que las bodas culminaran en el lecho nupcial. La niña se dedicó a ir a observar estos hechos todos los días y, además de pensar que se trataba de "casamientos", también creía que estas mujeres estaban enfermas y que, una vez casadas, morían. El desprecio por el sexo masculino habría sido el motivo por el cual Úrsula eligió el monasterio como estilo de vida. Cuenta que cuando era joven y le preguntaban si pensaba casarse respondía: "Pues yo, ¿Habría de consentir que con hombre me acostasen?; 'primero he de horcarme, o con una daga degollarme, o el pecho atravesarme'; y, advirtiendo que era pecado esto y podria irme al infierno, empesé a llorar y afligirme de nuevo" (123-4).

Como podemos observar, la escritura de Úrsula, que tiene como fin - por orden del confesor - contar sus pecados, supera a ratos ese mandato, pues la monja se toma el tiempo necesario para contar aquello que le sucedía de pequeña, lo que sentía, lo que pensaba, lo que soñaba. Se trata de escritos sumamente obedientes, se relata y recalca este carácter durante todo el relato, pero que, en este ataque a los hombres, pareciera que lo hiciera también a su propio confesor. Pero, tal y como lo afirmara Adriana Valdés, sor Úrsula Suárez maneja en su texto una doble autoridad, pues las voces que la monja escucha vendrían directamente de Dios y, de esta manera, el confesor no podría ir en su contra. Y es así como también organiza su discurso Hildegard. Afirmando que las palabras que profiere no son de ella sino de Dios, nadie puede debatir su contenido ni su forma.

Tanto Hildegard como Úrsula atribuyen sus dones a su pequeñez. Es gracias a su pequeño nombre femenino que pueden elaborar un discurso fuera del alcance masculino. Y así, pareciera que estas mujeres tuercen la mano masculina desde la misma trampa que esta le tiende, pues así funcionaría, según Foucault, el ejercicio de poder:

hace de modo que el ejercicio del poder no se agregue del exterior, como una coacción rígida o como un peso, sobre las funciones en las que influye, sino que esté en ellas lo bastante sutilmente presente para aumentar su eficacia aumentando él mismo sus propias presas (125).

El confesor se inmiscuye en el texto de la visionaria para, desde su interioridad, influenciarla y vigilarla, ejerciendo así su poder. Esta medida surge porque ya disponer del tiempo y del espacio de estas mujeres no basta: su habla parece desentenderse del discurso oficial de la Iglesia que las oprime, pero que a la vez las resguarda por medio de las voces y visiones. La manera en que la disciplina puede triunfar es, según Foucault, debido "al uso de instrumentos simples: la inspección jerárquica, la sanción normalizadora y su combinación en un procedimiento que le es propio: el examen" (199). Y es evidente cómo los confesores organizan este aparataje de dominación mediante la vigilancia de los 


\section{Jimena Castro Godoy}

discursos de estas mujeres, discurso que se les escapa y que se disgrega de este verdadero observatorio que significa la confesión. Hildegard adquiere un poder social impensable, que va desde la fundación de conventos en contra de la voluntad del obispo de la zona, hasta la fama popular que alcanzó entre los fieles, quienes le escribían para pedirle los más insólitos consejos. Úrsula desafía a su confesor en reiteradas ocasiones, relatando que incluso el mismo Dios le ordenaba realizar lo contrario a lo que el sacerdote le instruía.

La construcción de la celda (habitación de la monja), del convento cerrado y de la confesión responden a la noción de que "el aparato disciplinario perfecto permitiría verlo todo permanentemente con una sola mirada" (Foucault, 203). En la vida monástica se construye todo para vigilar y castigar: tiempo, espacio y cuerpo se estructuran para la aniquilación del individuo. Pero, como hemos visto, también de ahí surgieron voces que, estratégicamente, lograron hacerse escuchar.

$\mathrm{Y}$ es por medio del mismo aparato de la visualidad que vigila cómo Hildegard y Úrsula logran también exponer su espiritualidad. Dentro del texto testimonial de Úrsula Suárez nos encontramos con una serie de acontecimientos de carácter ecfrástico en que se describen sueños y vivencias sobrenaturales siempre bajo el alero de la mirada y la audición. Son muchos los episodios visionarios que narran experiencias bastante particulares. En ellas se vislumbra una enorme participación del cuerpo y de las sensaciones, donde también el tono dramático forma parte de la narración:

Parecióme que cuando desía esto veí el cielo abierto y como un trono en medio, cubierto con velo; no veía resplandores divinos, ni sé desirlo; distinguía habían personajes y también sentía se movían (...) No refiero aquí mis rasones ingnorantes; mas dijéronme: "Pide tú también"; respondí yo: "Eso no, que en mí será atrevimiento: desde la tierra sólo miraré lo que pasa en el cielo; vayan santos de mi corasón pidiendo" (221).

A pesar de la multiplicidad de relatos de este formato, la monja repetirá que no sabe nada de lo que le está pasando: "No sabía yo que Dios hablaba en el interior, como del mesmo corasón, sino que de otra suerte se le oía la vos; y por eso pensaba que yo sola hablaba" (184). Con esto va alterando la imagen de la autoridad del confesor que decae ante la de Dios, quien habla desde ella misma, desde su corazón. Es ahora su propio cuerpo el que se convierte en el vehículo para sus visiones y audiciones. Al igual que Hildegard von Bingen: la abadesa benedictina, como mencioné, utiliza también su cuerpo como una treta lingüística que se vincula con la visión. 
Sin embargo, no es novedosa la utilización del cuerpo como vehículo de la visión. ${ }^{6}$ Pero sí hay algo que estas dos mujeres acarrean fuera de lo que podría saberse propio del discurso místico femenino: ninguna abusa del lenguaje erótico ni narra una flagelación exagerada de su cuerpo. Al contrario. Recordemos cómo Hildegard fue reprendida por otra monja por el uso de hábitos blancos y joyas de oro en su convento. En otra ocasión, la utilización de la música en sus liturgias cuando le había sido prohibida le significó un reproche epistolar. Hildegard respondió con convicción que una esposa de Cristo debe vestir con la dignidad que este rango merece. Úrsula también manifiesta en repetidas ocasiones cierta celebración de su materialidad. A pesar de que se observa a sí misma y a las monjas en general como "imágines" (181) incapaces de sentir amor carnal, sí muchas veces demuestra la habilidad de sentir amor divino: "En una ocasión, tanto el cuerpo se me ensendió, que el corasón me aleó, no cabiéndome en el pecho, que se me suspendía el resuello, paresiendo que la alma daba un vuelo y que le era pesada carga el cuerpo" (192). Como mencionara Adriana Valdés (2003), la particularidad que habita en el cuerpo de Úrsula Suárez es que su mirada "mira también hacia el mundo, aunque sea a veces de reojo, escondida desde el coro, o ciertamente tras las rejas del locutorio" (Valdés, 2003:198). Por eso es que creo que cuando la visión penetra ya el cuerpo, el espacio de la vigilancia ha perdido lugar en el examen. A pesar de la aparente uniformidad que le es dada a la monja en su vestir y actuar, ambas se las arreglan para transgredir esta uniformidad: Hildegard y sus hermanas usando hábitos lujosos, Úrsula disfrazándose en el locutorio para engañar a los hombres que la visitaban.

En este sentido, ya no se trataría de la imagen que otro se forma de la monja, sino que de la imagen que ellas van elaborando de sí mismas. Por medio de sus visiones, de los elementos materiales que las rodean, los rosarios, los grabados, el vía crucis, las flores y ornamentos del altar, van armando un inventario visual que redunda también en sus experiencias sobrenaturales. Así, el ojo, el mismo órgano que las vigila, es el órgano que las redime. La visualidad en los conventos, como advirtió Jeffrey Hamburger, es imposible de entender sin considerar la tensión que las monjas guardan con sus confesores. Si no contáramos con este ejercicio —el del examen, o cura monialum - las obras conventuales guardarían una naturaleza completamente diferente. Creo que en la tensión establecida entre ambas partes es donde habita su atractivo estético. Quedaría pendiente observar con mayor atención a las impresiones del confesor,

\footnotetext{
${ }^{6}$ Jeffrey Hamburguer en The Visual and the Visionary indica que la relación entre cuerpo y discurso tiene un fundamento teológico, pues todo el cristianismo se basa en que Dios ha creado al hombre a su imagen y semejanza y que, además, se ha encarnado (27). Esta idea fue captada por las monjas del Medioevo que él estudia y en cuyo tema indaga también Caroline WalkerBynum en sus múltiples estudios sobre cristianismo y corporalidad.
} 


\title{
Jimena Castro Godoy
}

a sus intenciones y su posible goce estético al leer y observar estas obras monjiles.

\author{
Doctora (c) en Estudios Americanos, Universidad de Santiago* \\ Instituto de Estudios Avanzados \\ Román Díaz 89, Providencia, Santiago (Chile) \\ jimenacastrogodoy@gmail.com
}

\section{OBRAS CITADAS}

Araya, Alejandra. "El discurso sofocado: el epistolario confesional de una monja del siglo XVIII", en Revista Mapocho, 53. 2003:161-192.

Cánovas, Rodrigo. "Úrsula Suárez (monja chilena, 1666-1749): la autobiografía como penitencia", en Revista Chilena de Literatura, 35: 97-115, 1990.

Cirlot, Victoria; Garí, Blanca. La mirada interior. Escritoras místicas y visionarias en la Edad Media. Madrid, Siruela, 2008.

Cirlot, Victoria. Vida y visiones de Hildegard von Bingen. Madrid: Siruela, 2009.

Evangelisti, Silvia. Nuns. A History of Convent life. New York: Oxford University Press, 2007.

Foucault, Michel. Vigilar y castigar. Nacimiento de la prisión. México: Siglo XXI, 2009.

Poutrin, Isabelle. Le voile et la plume. Madrid: Bibliotèque de la Casa de Velásquez, 1995.

Suárez, Úrsula. Relación autobiográfica. Santiago: Biblioteca Antigua Chilena, 1984.

Valdés, Adriana. "Escritura de monjas durante la Colonia. El caso de Úrsula Suárez en Chile", en Revista Mapocho, 31. 1992:149-166.

------ "Úrsula Suárez. "En torno a su cuerpo", en Revista Chilena de Literatura, 62: 183-204, 2003. 